\title{
PSYCHOSOCIAL AND FUNCTIONAL CORRELATES OF NUTRITION AMONG COMMUNITY-DWELLING OLDER ADULTS IN IRELAND
}

\author{
R. ROMERO-ORTUNO, A.M. CASEY ${ }^{1}$, C.U. CUNNINGHAM, S. SQUIRES, D. PRENDERGAST, \\ R.A. KENNY, B.A. LAWLOR
}

1. All correspondence to: Anne-Marie Casey, Tel.+353 1491 4609; Email: caseya1@tcd.ie

\begin{abstract}
Objectives: To examine psychosocial and functional correlates of nutrition in a nonrandom sample of Irish community-dwelling older adults. Design: Cross-sectional observational study. Setting: Technology Research for Independent Living (TRIL) Clinic, a comprehensive geriatric assessment facility in St James's Hospital, Dublin. Data were collected from participants by medical personnel (physical assessments) and psychologists (questionnaires), between August 2007 and May 2009. Participants: 556 participants (388 females; 168 males) ranging in age from 60-92 years (Mean 72.5 years, SD 7.1). All were community-dwelling and provided informed consent. Measurements: The Nestlé Mini-Nutritional Assessment (MNA®), Time to get up and go (TUG) and the Lubben Social Network Scale-18 (LSNS-18) were used to assess nutrition, functional mobility and social support. Methods: Multivariate binary logistic regression was used to examine the association between social support or mobility and nutritional status, whilst controlling for possible confounders (age, gender, living alone and material deprivation). Results: The strongest predictors of abnormal nutritional status were mobility $(\mathrm{p}<0.001)$ and social support $(\mathrm{p}=0.005)$. Other significant predictors of nutritional risk were age $(\mathrm{p}=0.032)$ and deprivation $(\mathrm{p}=0.018)$. Conclusion: The results emphasise the importance of mobility and social supports in mediating nutritional outcomes in Irish community-dwelling older adults.
\end{abstract}

Key words: Nutrition, social support, Mini-Nutritional Assessment, Lubben Social Network Scale, older adults.

\section{Introduction}

Nutrition is an important determinant of the health status of older people $(1,2)$ and can have an impact on physical and psychological wellbeing (3). Successful ageing poses challenges for medical, social and psychological practitioners. While the number of older adults increases worldwide, it is important to identify factors that impact the nutrition status and well being in older people (4).

\section{Nutrition}

A review of the Mini-Nutritional Assessment (MNA®) literature (112 studies with over 30,000 older adults worldwide) indicates a $1 \%$ mean prevalence of malnutrition in healthy community dwelling older people, $4 \%$ in outpatients; $20 \%$ in hospitalised patients and $37 \%$ in institutional care (5). In Ireland, one study showed 3\% prevalence of malnutrition (i.e. BMI below $20 \mathrm{Kg} / \mathrm{m}^{2}$ ) in community dwelling older adults (6), and another showed $16 \%$ prevalence in older people admitted to hospital (7). This contrasts with $29 \%$ estimates from England (London) and 36\% from Sweden in prevalence rates of older people at risk of malnutrition admitted to hospitals (7).

\section{Social Support and Nutrition}

Social support refers to support and assistance provided to individuals, regularity of contact and perceived satisfaction with support (8). Older adults with limited social support may be isolated and show an increased vulnerability to poor health outcomes $(9,10)$. In particular, social support is one of the factors related to improved nutritional outcomes $(11,12)$. An important means of maintaining social support is eating with others. The impact of social support on nutrition may vary depending on a number of factors. These include the amount, the range, frequency and closeness of contact with social supports which can change as a person ages (14).

Socio-economic status may also influence both the affordability and quality of food intake. Married couples may be able to afford better food and are more likely to eat more regularly than widowed or single people (13). Without the social interaction, living or eating alone can lead to older people eating less often with a lowered nutritional intake which affects nutritional health outcomes $(15,16)$. As someone ages, it is necessary to make dietary changes to meet new physiological demands. Decreased levels of social support can make it difficult for older adults to make these dietary changes and may lead to increased risk of malnutrition and poor health outcomes (17). Another important strong predictor of nutritional outcomes and social isolation may be mobility (13). Poor mobility of older adults may lead to higher dependence on support networks to avail of adequate provisions. The aim of the current study is to determine the psychosocial and functional correlates of nutrition in an Irish sample of community-dwelling older people.

\section{Methodology}

\section{Sample}

The study involved 556 community dwelling subjects attending the Technology Research for Independent Living 


\section{CORRELATES OF NUTRITION AMONG IRISH OLDER ADULTS}

(TRIL) Clinic at St James's Hospital, Dublin (www.stjames.ie). TRIL is a collection of research projects addressing the physical, cognitive and social aspects of ageing. The TRIL Clinic offers an outpatient clinical service to communitydwelling people over 60 years of age, in the form of a comprehensive geriatric assessment that incorporates the use of technologies and collection of biomarkers to measure risk factors for falls, cognitive decline and lack of social connectedness. The TRIL Clinic is nationally advertised in newspapers, the TRIL website (www.trilcentre.org) and information leaflets distributed in outpatient clinics at $\mathrm{St}$ James's Hospital and general practitioners' clinics in the catchments of St James's Hospital. All participants participated voluntarily were community-dwelling, aged 60 and over, able to mobilise independently with or without mobility aid and able to provide informed consent. Local Research Ethics Committee approval was obtained (SJH/AMNCH Research Ethics Committee approval reference number 2007/06/13). All participants gave their informed consent prior to their inclusion in the study.

\section{Design}

Participants were interviewed at the TRIL Clinic at St James's Hospital in Dublin. All participants underwent a structured clinical assessment which included medical and falls history by physicians, and cognitive and psychosocial assessments by psychologists.

\section{Primary Measures}

\section{Mini Nutritional Assessment (MNA®)}

MNA ${ }^{\circledR}$ has been shown to be a reliable screening and assessment tool for health professionals to use as part of a comprehensive geriatric assessment (5). This 18-item assessment measures anthropometric measurements, biological markers, dietary intake, clinical and functional evaluations of cognition, medications and independent activities of daily living. Individual items relate to loss of appetite, digestive problems, chewing or swallowing difficulties, weight loss, digestive problems, mobility, psychological stress, neuropsychological problems, body mass index (BMI) and calf circumference, with lower scores indicating higher nutritional risk. The MNA ${ }^{\circledR}$ can be used as a continuous or categorical variable (the latter categories being: normal, at risk of malnutrition, and malnourished). In our study, we used 'abnormal MNA' as outcome, which groups together the 'at risk' (sample prevalence $=6.7 \%$ ) and the 'malnourished' $(0.5 \%)$ categories.

\section{Lubben Social Network Scale-18 (LSNS-18)}

The LSNS-18 was used to assess perceived social support (18). The 18 item scale identifies four dimensions: total social support; family networks; friendship networks, and networks of neighbours. The LSNS-18 is available online (http://www 2.bc.edu/ norstraj/default.html) and has been previously used in relation to nutrition $(12,19)$ although not in an Irish context.

National Irish Deprivation Score 2006 (NIDS)

NIDS is based on the electoral division of residence and is available on the website of the Small Area Health Research Unit of Trinity College Dublin (20). The NIDS is a composite measure of four dimensions: social class, unemployment, housing tenure type and car ownership.

\section{Time to get Up and Go (TUG)}

The general mobility of the participants was assessed by the Time to get Up and Go (TUG) test (21). TUG measures tasks involved in mobility which include the time it takes an individual to rise from an arm chair, walk 10 feet from the chair, turn, return to the chair and sit again on the chair.

\section{Secondary Measures}

Demographic factors included age and gender. The Charlson Co-morbidity Index (22) examined co-morbid illnesses. Psychosocial variables included cognition measured by the Mini-Mental State Examination (MMSE) test (23); depression was measured by the Centre for Epidemiological Studies Depression Scale (24) (CESD-8); the Eysenck Personality Inventory (25) (EPI) measured personality traits (extraversion and neuroticism), and the De Jong Gierveld (26) measured total loneliness (TL), social loneliness (SL) and emotional loneliness (EL).

\section{Statistical methods}

Data were analysed using SPSS 16.0. Sample descriptives were given as mean with standard deviation (SD), or percentages as appropriate. Bivariate comparisons of demographic, medical and psychosocial variables were conducted with Mann-Whitney U test (continuous variables), and Chi-squared (dichotomous variables), as appropriate.

Binary logistic regression was conducted to assess whether our social support variable, LSNS-18, significantly predicted abnormal MNA ${ }^{\circledR}$ in the face of the following possible confounders: age, gender, living alone, general mobility and material deprivation. The maximum number of variables in the regression model was constrained by the sample size. Age was entered as a continuous variable. Gender $($ male $=0$, female $=1)$ and living alone $(\mathrm{no}=0$, yes $=1$ ) were entered as dichotomous variables. Material deprivation was entered as a continuous variable using the most recent NIDS. Older adults with poor mobility may be at a higher risk of malnourishment as they are more likely to be dependent on others for access to purchase, prepare and cook food $(27,28)$. The significance level of $\mathrm{p}<0.05$ was set for all statistical procedures.

\section{Results}

Comparison statistics for the 'normal' and 'abnormal' MNA® groups are presented in Table 1 . Overall, only $7.2 \%$ of the sample $(\mathrm{N}=40)$ were identified as malnourished $(\mathrm{N}=3$, 
$0.5 \%)$ or at risk of malnutrition $(\mathrm{N}=37,6.7 \%)$. There were no statistically significant differences between normal and abnormal MNA groups for gender, social loneliness or extraversion scores. However, significant differences were observed for age, co-morbid illness, cognition, depression symptoms, emotional loneliness, and neuroticism score.

Table 1

Comparison of baseline characteristics between older adults with normal nutrition and abnormal nutrition

\begin{tabular}{llll}
\hline & $\begin{array}{l}\text { Normal MNA } \\
(\mathbf{N}=\mathbf{5 1 6})\end{array}$ & $\begin{array}{l}\text { Abnormal MNA } \\
\mathbf{( N = 4 0 )}\end{array}$ & $\begin{array}{l}\text { Significance } \\
\text { of the } \\
\text { difference }\end{array}$ \\
\hline Demographic Variables & $\%$ & $\%$ & \\
Female & 69.8 & 70 & $1.000^{\mathrm{b}}$ \\
Male & 30.2 & 30 & $1.000^{\mathrm{b}}$ \\
Living alone & 39.3 & 40 & $0.798^{\mathrm{b}}$ \\
Age (years) & Mean (SD) & Mean (SD) & \\
NIDS & $72.08(6.9)$ & $78.22(7.3)$ & $<0.001^{\mathrm{a}}$ \\
Bio-Medical Variables & $.2(2.06)$ & $1.92(2.62)$ & $<0.001^{\mathrm{a}}$ \\
Charlson Co-morbidity Index & $3.74(3.2)$ & $7(2.9)$ & $<0.001^{\mathrm{a}}$ \\
TUG & $9.59(3.97)$ & $16(7.9)$ & $<0.001^{\mathrm{a}}$ \\
Psychosocial Variables & & & $<0.001^{\mathrm{a}}$ \\
MMSE & $28(2.3)$ & $26(2.9)$ & $0.001^{\mathrm{a}}$ \\
CESD-8 & $1.7(1.9)$ & $3.1(2.6)$ & $<0.001^{\mathrm{a}}$ \\
LSNS-18 & $47.4(12)$ & $37.8(14.3)$ & $0.005^{\mathrm{a}}$ \\
De Jong Gierveld - TL & $1.3(1.4)$ & $2.05(1.7)$ & $0.009^{\mathrm{a}}$ \\
De Jong Gierveld - EL & $0.8(0.9)$ & $1.3(1.4)$ & $0.067^{\mathrm{a}}$ \\
De Jong Gierveld - SL & $0.5(0.8)$ & $0.76(0.9)$ & $0.814^{\mathrm{a}}$ \\
EPI - Extraversion & $11.6(4.0)$ & $11.61(3.9)$ & $0.003^{\mathrm{a}}$ \\
EPI - Neuroticism & $9.82(4.5)$ & $12.47(5.2)$ & \\
\hline
\end{tabular}

a. Mann Whitney U test (2-sided); b. Chi squared test

Table 2

Logistic regression predicting who will have abnormal MNA®

\begin{tabular}{lllllll}
\hline Variable & $\begin{array}{l}\text { Regression } \\
\text { coefficient, } \\
\text { unstandar- } \\
\text { dized (B) }\end{array}$ & $\begin{array}{l}\text { Standard Significance Odds Ratio } \\
\text { Error }\end{array}$ & $\begin{array}{l}\text { 95.0\% C.I.for Odds } \\
\text { level (p) } \\
\text { Ratio } \\
\text { Lower }\end{array}$ & Upper \\
\hline TUG & .105 & .030 & $<.001$ & 1.111 & 1.048 & 1.177 \\
LSNS-18 & -.046 & .016 & .005 & .955 & .926 & .986 \\
NIDS 2006 & .178 & .075 & .018 & 1.195 & 1.031 & 1.385 \\
Age & .064 & .030 & .032 & 1.066 & 1.005 & 1.131 \\
Lives alone & -.419 & .383 & .274 & 1.520 & 718 & 3.218 \\
Gender & -.205 & .412 & .620 & .815 & .363 & 1.828 \\
Constant & -7.081 & 2.325 & .002 & .001 & & \\
\hline
\end{tabular}

Binary logistic regression with the enter selection procedure was performed to assess the impact of a number of predictor variables on nutritional risk (Table 2). The model contained the following independent variables: age, gender, LSNS-18, living alone, NIDS, and TUG. The Nagelkerke "pseudo" R2 estimate was 0.277 indicating that approximately $28 \%$ of the variance in whether subjects had a normal MNA® can be predicted from the linear combination of the independent variables. Overall, 93\% of the subjects were predicted correctly; however, the model was much better at predicting who would have a normal MNA ${ }^{\circledR}(99 \%$ correct) than who would have an abnormal MNA ${ }^{\circledR}(15 \%$ correct). The overall model was statistically significant, $\chi^{2}=65.948, \mathrm{df}=6, \mathrm{~N}=556, \mathrm{p}<0.001$. Living alone was not a significant predictor of nutritional risk $(p=0.274)$, and gender was not a significant predictor either $(\mathrm{p}=.620)$. All other predictors were significantly associated with poor nutritional outcomes $(p<0.05)$. The strongest predictor of nutrition was mobility $(\mathrm{p}<0.001)$. In the face of all the other predictors, social support was the second strongest predictor $(\mathrm{p}=0.005)$.

\section{Discussion}

The current study shows that mobility was associated with greatest risk of poor nutritional health outcomes. Mobility is a strong predictor of disability in older adults (19) and is associated with social isolation and poor nutritional outcomes (13). Results from this study indicate that older adults with limited social supports are at risk of poor nutritional outcomes. It is a common held belief that an active life helps preserve physical and psychological well being. This study provides more evidence that social support is particularly important to the health status of older adults $(18,12)$. Across life span development, the need to belong is a strong human incentive (29) and has been found to be a significant factor of successful ageing in the present study. This study also highlights that age and deprivation have an effect on nutritional outcomes, and that older adults who are socially deprived are more likely to be undernourished.

Although the literature indicates that married couples may have less nutritional risk $(30,31)$, this study which had $39.4 \%$ of older adults living alone, did not find that living alone was a significant independent predictor of nutritional outcomes. The percentage of older adults living alone increased from $20 \%$ in 1981 to $29 \%$ in 2002 (32.) The findings in the present study are supported by emerging evidence that living alone is not necessarily a negative factor (33). Indeed, maintaining independence at home may be a key factor in successful ageing for older adults (34). This novel finding highlights the protective effects of social supports on nutritional outcomes, even if living alone. While other studies found a gender difference in the association of social supports and nutrition (15), this was not supported in this study (Table 2).

There were statistically significant differences in cognition as measured by the MMSE between normal and abnormal MNA groups (Table 1). However, the means were high for both groups $(\geq 26)$ and above the $<23$ cut-off point for screening dementia in an Irish community setting (35), indicating that cognition was not likely to affect self-reports of social supports in this study.

Differences in depressive symptoms, emotional loneliness and neuroticism were also found to be statistically significant between both groups but no differences were found for social loneliness and extraversion between the normal and abnormal MNA groups. The association of depression, emotional loneliness and neuroticism are supported by personality theory 


\section{CORRELATES OF NUTRITION AMONG IRISH OLDER ADULTS}

(36): the cognitive bias model proposes that negative intrapersonal cognitive evaluations of self and other are reported by people who have depression, low self esteem and high neuroticism scores, which can contribute to loneliness. Such individuals with low extraversion scores may be unable to form social relationships and maintain social networks. Based on these theories, the normal and abnormal MNA groups may have differed in the ability to form and maintain social relationships, in the negative evaluations of their social supports, or both.

Mobility and social supports are potentially modifiable factors which should be included in comprehensive clinical assessments of nutritional status and overall health of older adults. In 2010, ongoing research in Technology Research for Independent Living (TRIL) clinic at St James's Hospital will include assessments of mobility, social supports and nutrition to comprehensively evaluate aging and frailty of older adults in Ireland. Provision of education, improving lifestyle choices and perceived supports may optimise nutritional health and facilitate adaptation to the process of aging. Supportive interventions in social engagement may improve health outcomes with older adults $(37,38)$. Among these interventions, one could include recommendations for public health nurse schemes to promote and optimise social support, diet and nutrition, health and exercise (39) and interventions which promote behaviour change in older adults (40).

One of the strengths of the present study is the insight it provides into successful ageing in Irish older adults and provides novel findings on the lack of effect of living alone on the nutritional outcome under consideration. In addition, the study employed well validated tests and questionnaires of nutrition, functional mobility and social supports which allow the results to be interpreted objectively. Similar studies used smaller sample sizes (12) and found differences between community dwelling and long term care (19). The present study provides evidence using a larger sample size and contributes to the emerging evidence on community dwelling older adults who are living alone.

A limitation of the current study is the cross sectional design which limits our understanding of the causality of the associations revealed in the study. While patterns of social support are associated with nutritional status in this study, the underlying pathways are not yet established. Another potential weakness is that the assessment of social support networks is based on self-report and not on an independent assessment. These preliminary findings would be better understood in a longitudinal investigation of a population based sample to establish the causal link between social supports and nutritional status of older adults.

\section{Conclusion}

In this study, we investigated the psychosocial and functional correlates of nutrition among community-dwelling older adults in Ireland. The strongest predictors of abnormal nutritional status were mobility, social support, age and deprivation. This study emphasises the importance of mobility and social support in predicting nutritional status in community-dwelling older adults. Mobility and kinship have been highlighted as important for survival as early as in the prehistoric Sahara (41). Today, $16.1 \%$ of the Irish population is sixty years and over and it is estimated that by 2050, 29.4\% will be sixty and over (42), which will have an impact on the rising costs of health care in Ireland. Age Concern England's 'Hungry to be heard Report' (2006) (43) found that six out of ten older adults in hospital are at risk of poor nutritional outcomes. In this study, we found that $7.2 \%$ of community dwelling older adults are hungry to be heard too. To maintain healthy ageing, initiatives in the community which promote formal and informal social supports may improve health outcomes with older adults.

This research was completed as part of a wider programme of research within the TRIL Centre, (Technology Research for Independent Living). The TRIL Centre is a multidisciplinary research centre, bringing together researchers from UCD, TCD, NUIG \& Intel, funded by Intel, IDA Ireland and GE Healthcare. www.trilcentre.org

Financial disclosure: None of the authors had any financial interest or support for this paper.

\section{References}

1. Wells JL, Dumbrell AC. Nutrition and aging: assessment and treatment of compromised nutritional status in frail elderly patients. Clinical Interventions in Aging 2006;1:67-79.

2. Krondl M, Coleman P, Lau D. Helping Older Adults Meet Nutritional Challenges. Journal of Nutrition for the elderly 2008;27:205-20.

3. Pirlich M, Lochs H. Nutrition in the elderly. Best Practice \& Research Clinical Gastroenterology 2001;15(6):869-84.

4. Faes M, Iersel MV, Rikkert MO. Methodological issues in geriatric research. J Nutr Health Aging 2007;11(3):254-60.

5. Guigoz Y. The Mini Nutritional Assessment $(\mathrm{MNA} \AA)$ review of the literaturewhat does it tell us? J Nutr Health Aging 2006;10:466-87.

6. Corish CA, Kennedy NP. Anthropometric measurements from a crosssectional survey of Irish free-living elderly subjects with smoothed centile curves. British Journal of Nutrition 2003;89:137-45.

7. Meier R, Stratton R. Basic Concepts in nutrition: epidemiology of malnutrition. ESpen, The European e-Journal of Clinical Nutrition and Metabolism 2008;3(4):e618e170.

8. Hooyman NR, Kiyak HA. Social Gerontology: a multidisciplinary perspective. Boston: Allyn and Bacon; 2008.

9. Sahyoun NR. Barriers to the consumption of fruits and vegetables among older adults. Journal of Nutrition for the elderly 2005;24(4):5 - 21.

10. White AM, Philogene S, Fine L, Sinha S. Social support and self reported health status of older adults in the United States. American Journal of Public Health 2009;99(10):1872-8

11. McIntosh WA, Shifflett PA, Picou JS. Social support, stressful events, strain, dietary intake, and the Elderly. Medical Care 1989;27(2):140-53.

12. ohnson CSJ. Psychosocial correlates of nutritional risk in older adults. Canadian Journal of Dietetic Practice and Research 2005:95-7.

13. Locher JL, Ritchie CS, Roth DL, Baker PS, Bodner EV, Allman RM. Social isolation, support, and capital and nutritional risk in an older sample: ethnic and gender differences. Social Science \& Medicine 2005 Feb;60(4):747-61.

14. Silverman P, Hecht L, McMillin JD. Social support and dietary change among older adults. Ageing and Society 2002;22:29-59.

15. Friel S, Kelleher CC, Nolan G, Harrington J. Social diversity of Irish adults nutritional intake. European Journal of Clinical Nutrition 2003 Jul;57(7):865-75.

16. Sampson G. Weight loss and malnutrition in the elderly. Australian Family Physician 2009;38(7):507-10.

17. Kim KHC, McIntosh WMA, Kubena KS, Sobal J. Religion, social support, food related social support, diet, nutrition, and anthropometrics in older adults. Ecology of Food and Nutrition 2008;47:205-28. 


\section{JNHA: NUTRITION}

18. Lubben JE, Gironda M, editors. Centrality of social ties to the health and wellbeing of older adults: Springer Publishing Company; 2003.

19. Johnson CSJ, Mahon A, McLeod W. Nutritional, functional and psychosocial correlates of disability among older adults. J Nutr Health Aging 2006;10:45-

20. Kelly A, Teljeur C. The National Deprivation Index for Health and Health Services Research. Dublin: SAHRU Department of Public Health and Primary Care, Trinity College Dublin; 2007.

21. Mathias S, Nayak USL, Isaacs B. Balance in elderly patient" The "Get Up and Go" Test. Archives of Physical Medical Rehabilitation 1986;67:387-9.

22. Charlson ME. A new method of classifying prognostic comorbidity in longitudinal studies: development and validation. Journal of Chronic Diseases 1987;40(5):373-83.

23. Folstein MF, Folstein SE, McHugh PR. Mini-mental state examination. Psychological Assessment Resources. 1975.

24. Irwin M, Artin KH, Oxman MN. Screening for Depression in the Older Adult Criterion Validity of the 10-Item Center for Epidemiological Studies Depression Scale (CES-D). Archives of Internal Medicine 1999;159(15):1701- 4.

25. Eysenck HJ, Eysenck SBG. Manual of the Eysenck personality inventory. Hodder and Stoughton Limited, Sevenoaks; 1984

26. de Jong Gierveld J, Van Tilburg T. A 6-item scale for overall, emotional and social loneliness. Research on Aging 2006;28(5):582-98.

27. Morley JE. Nutritional problems of the elderly. Contemporary Nutrition 1987;12(1).

28. Ho SC, Woo J, Lau J, Chan SG, Yuen YK, Chan YK, et al. Life satisfaction an associated factors in older Hong Kong Chinese. J Am Geriatr Soc 1995;43(3):252-5.

29. Baumeister R, Leary M. Motivational Science: Social and Personality Perspectives. In Higgins ET \& Kruglanski AW ed. New York: Psychology Press; 2000.

30. Friel S, Kelleher CC, Nolan G, Harrington J. Social diversity of Irish adults nutritional intake. European Journal of Clinical Nutrition 2003;57(7):865-75.

31. Sampson G. Weight loss and malnutrition in the elderly. Australian Family Physician 2009;38(7):507-10
32. Fahey T, Maitre B, Nolan B, Whelan CT. A social portrait of older people in Ireland. In: ESRI. Dublin; 2007.

33. Victor C, Scambler S, Bond J, Bowling A. Being alone in later life: loneliness, social isolation and living alone. Reviews in Clinical Gerontology 2000;10:407-17.

34. Victor C. The Social Context of Ageing; a textbook of gerontology. New York: Routledge; 2005.

35. Cullen B, Fahy S, Cunningham CJ, Coen RF, Bruce I, Greene E, Coakley D, Walsh $\mathrm{JB}$, Lawlor BA. Screening for dementia in an Irish community sample using MMSE: a comparison of norm-adjusted versus fixed cut-points. Int Ger Psych 2005;20:371376.

36. Levin I, Stokes JP. An examination of the relation of individual difference variables to loneliness. Journal of Personality 1986;54:717-733.

37. Jorm AF. Social networks and health: It's time for an intervention trial. Journal of Epidemiological Community Health 2005;59:537-538.

38. Golden J, Conroy RM, Lawlor BA. Social support network structure in older people: Underlying dimensions and association with psychological and physical health. Psychology, Health \& Medicine 2009;14:280-90.

39. Skarupski KA, Pelkowski JJ. Multipurpose senior centers: opportunities for community health nursing. Journal of Community Health Nursing 2003;20:119-32.

40. Marquez DX, Bustamante EE, Blissmer BJ, Prohaska TR. Health promotion for successful aging. American Journal of Lifestyle Medicine. 2009;3:12-9.

41. Tafuri MA, Bentley RA, Manzi G, diLernia S. Mobility and kinship in the prehistoric Sahara: Strontium isotope analysis of Holocene human skeletons from the Acacus Mts. (South Western Libya). Journal of Anthropological Archaelogy 2006;25:390402.

42. United Nations. 2010; Available from: http://www.un.org/esa/population /publications/ageing/ageing2009chart.pdf 